\title{
The properties of glass fibres after conditioning at composite recycling
}

\section{temperatures}

J. L. Thomason ${ }^{\#}$, L. Yang and R.Meier*

University of Strathclyde, Department of Mechanical and Aerospace Engineering, 75

Montrose Street, Glasgow G1 1XJ, United Kingdom.

\begin{abstract}
Results are presented on E-glass fibre properties after thermal conditioning up to $600^{\circ} \mathrm{C}$. Thermal conditioning led to up to $70 \%$ strength degradation. Tensile strength and failure strain of silane-coated fibres were relatively stable up to $250^{\circ} \mathrm{C}$ but exhibited a precipitous drop at higher conditioning temperatures. Unsized fibres exhibited a linear decrease in strength with increasing conditioning temperature. Little significant strength regeneration was obtained from a range of acid and silane post-treatments of heat conditioned fibres. A simple analysis of the cumulative fibre strength probability resulted in more useful understanding than the Weibull method. The modulus of both fibre types increased linearly with conditioning temperature. Evidence was found of a slow time-dependent reduction of glass fibre modulus during storage in an uncontrolled environment. The results are discussed in terms of the changes in surface coating and bulk glass structure during heat conditioning and the role of the glass fibre water content.
\end{abstract}

Keywords: A. Glass fibres; B. Mechanical Properties; E. Heat treatment; E. Recycling \# Corresponding author, E-mail: james.thomason@strath.ac.uk, Tel. 01415482691, Fax: 01415525105

*Current address - Technische Universität München, D-85748 Garching, Germany 


\section{Introduction}

The disposal of end-of-life composite products in an environmentally friendly manner is one of the most important challenges currently facing the industrial and academic composites community. It is projected that by 2015 the total global production of composite materials will significantly exceed 10 million tons which, at end-of-life, will occupy a volume of over 5 million cubic meters. Glass fibre reinforced composites account for more than $90 \%$ of all the fibre-reinforced composites currently produced. About $60 \%$ of this volume employs thermosetting matrix materials producing composites (GRP) that are difficult to recycle in an efficient manner. The perspectives on this issue have been recently highlighted due to the accelerating growth in the use of such composite materials in transportation and wind energy sectors [1-6]. A number of processes are available for recycling such composites [1,7]. Of these possible routes, thermal recycling is probably the most technologically advanced and has been piloted in the UK and Denmark. However, nearly all options deliver recycled fibres (which make up approximately $60 \%$ by weight of the composites) that suffer from a lack of cost competitiveness with pristine first-pass materials. A key factor in this equation is the huge drop in the performance of recycled glass fibre (80-90\%) in comparison to its original state $[1,7]$. Consequently, recycled fibres have a very poor performance to cost ratio, and in most cases are considered unsuitable for reprocessing and reuse as a valuable reinforcement of composites. A breakthrough in this field could enable such recycled glass fibres (RGF) to compete with pristine materials in many large volume composite applications. The development of an economically viable process for regenerating the properties of thermally recycled glass fibres would have major technological, societal, economical, environmental impacts. The reuse of these materials could result in a huge reduction in the environmental impact of the glass-fibre and composites industry where the replacement of pristine glass fibre products by RGF 
products would equate to a global reduction in $\mathrm{CO}_{2}$ production of 400,000 Tons/annum from reduced melting energy requirements alone. Furthermore, such a development would also reduce the need for an annual landfill disposal of 2 million Tons of composites. These developments would clearly be in line with the growing societal and environmental pressure to reduce the use of landfill disposal, increase the reuse of valuable raw materials resources, and reduce the release of $\mathrm{CO}_{2}$ to the atmosphere.

Processing temperatures in the production of glass fibre are significantly higher than GRP recycling temperatures. Nevertheless, earlier work has indicated that the room temperature tensile strength of glass fibre can be significantly reduced by annealing at temperature as low as $150^{\circ} \mathrm{C}$ [8]. More recent studies have also confirmed that room temperature glass fibre strength can be reduced by exposure to temperatures in the $300^{\circ} \mathrm{C}-600^{\circ} \mathrm{C}$ temperature range [9-12] which is typical of the many different potential GRP recycling processes. Similar behaviour has also been observed in silica and basalt reinforcement fibres $[13,14]$. We are currently engaged in research projects where the ultimate goal is the generation of the fundamental knowledge to enable cost-effective regeneration of the mechanical properties of glass fibres produced from thermal recycling of glass reinforced thermoset composites such as wind turbine blades. In this paper we report on the influence of thermal conditioning, at temperatures typical for GRP recycling up to $600^{\circ} \mathrm{C}$, on the properties of water sized and silane sized E-glass fibres. We also report initial results of a study on the use of acid and silane treatments on the strength of heat-treated fibres.

\section{Experimental}

Boron free E-glass fibres supplied by Owens Corning-Vetrotex were investigated in this work. The fibre rovings were produced on a pilot scale bushing and were received as 20 
$\mathrm{kg}$ continuous single end square edge packages. The rovings had a nominal tex of 1200 $\mathrm{g} / \mathrm{m}$ and a nominal fibre diameter of $17 \mu \mathrm{m}$. No sizing was applied to the water finished fibres which had only been sprayed using the normal water prepad cooling sprays under the bushing, these samples are referred to as water sized or unsized. The APS coated fibres were coated with a normal rotating cylinder sizing applicator containing a $1 \%$ volume $\gamma$-aminopropyltriethoxysilane (APS) hydrolysed solution in deionized water. All fibre packages were subsequently dried at $105^{\circ} \mathrm{C}$ for 24 hours. The fibres were used as received from the manufacturer. Heat treatment of both fibre types was conducted simultaneously to obtain samples with identical thermal history. $300 \mathrm{~mm}$ lengths of silane sized and water sized fibre strand with no visible damage were removed from the inside of the roving packages. The glass fibre strands were suspended on a specially constructed jig preventing any contact with, and therefore damage to, the fibres (see Figure 1). Heat conditioning was carried out in a Carbolite LHT6 high temperature oven for 15 minutes at temperatures in the range $250-600^{\circ} \mathrm{C}$. The jig was then removed from the oven and the samples allowed to cool naturally to room temperature.

For chemical post-treatment ACS reagent 37\% hydrochloric acid ( $\mathrm{HCl})$, APS, $\gamma$ glycidyloxypropyltrimethoxysilane (GPS) and mercaptopropyltriethoxysilane (SPS) were supplied by Sigma Aldrich in the UK. 10v\% $\mathrm{HCl}$ was prepared by diluting concentrated $\mathrm{HCl}$ with deionised water. $1 \%$ volume silane solution was prepared by mixing the silane with deionised water. APS was hydrolysed without $\mathrm{pH}$ adjustment, all other silanes were hydrolysed in water whose $\mathrm{pH}$ value had been adjusted to 5.1-5.3 prior to mixing. One silane blend was created by mixing the APS and SPS solutions in equal amounts. The solution were left for 24 hours to ensure full hydrolysis. Heat treated glass fibre bundles were completely immersed in the treatment solutions, one or 
two hours for acid treatment, 15 minutes for silane solution, at room temperature and then dried in an oven at $110^{\circ} \mathrm{C}$ for another 15 minutes.

Single fibres were meticulously separated from the glass fibre strands avoiding fibrefibre interactions or excessive fibre bending as much as possible. Individual fibres were glued onto a card tabs with a central window cut out to matched the desired gauge length for the test. Card frames were cut from $250 \mathrm{~g} / \mathrm{m}^{2}$ grade card and single fibres were fixed to the card at both sides of the window using Loctite ${ }^{\mathrm{TM}}$ Gel Superglue. A Nikon Epiphot Inverted optical microscope was used at 200x magnification to obtain a digital photo of each fibre. The cross-sectional area was calculated from individual average fibre diameters measured at five points along the gauge length. During handling of the fibre in the microscope, care was taken to avoid fibre damage through contact with the microscope objective. Single fibre tensile properties were determined following ASTM C1557-03 using an Instron 3342 universal testing machine equipped with a $10 \mathrm{~N}$ load cell. Sample gauge length was $20 \mathrm{~mm}$ for both fibre types and approximately 75 fibres were tested at each condition. The tensile testing strain rate used was $1.5 \% / \mathrm{min}$ and all the tests were carried out at room temperature and $50 \%$ relative humidity. Only the tests where the sample broke along the gauge length at a distance greater than $3 \mathrm{~mm}$ from the clamps were used for further data processing.

\section{Results and Discussion}

\subsection{Fibre diameter distribution}

Over the course of the investigation the diameters of more than 1200 individual glass fibres were measured using optical microscopy. The results are summarised in Table 1 which reveals the relatively large distribution in fibre diameters present in commercially produced glass fibre reinforcements. Fibre diameter is an important parameter in 
defining the final performance of fibre reinforced composites and is related to several parameters including the internal diameter of the bushing tip, the velocity of molten glass flow, and attenuation rate [15]. For a given glass-fibre manufacturing configuration it is the variation of the molten glass flow that mainly accounts for fibre diameter distribution. The variation in the viscosity of glass melt is believed to be caused by the temperature distribution across the bushing [15]. In the case of single fibre strength and modulus these fibre diameters are used to calculate the fibre cross section. Examining the values for minimum and maximum fibre diameter in Table 1 it can be seen that using only a manufacturers nominal fibre diameter or a single average value of the distribution can lead to up to a $78 \%$ error in the value of fibre cross section. This would translate directly into errors of similar magnitude in the fibre modulus and strength. This large range in the measured diameters of glass fibres emphasises the need to determine individual fibre diameters prior to each single fibre test and not use average or datasheet values.

\subsection{Single fibre testing results}

The results for the average single fibre strength of silane sized and water sized fibres after heat treatment are shown in Figure 2 and the fibre strain at failure is shown in Figure 3. The results indicate that thermal conditioning caused a considerable strength reduction for both silane-sized and water-sized fibre samples, with a loss of over $70 \%$ of the original strength in the case of conditioning at $600^{\circ} \mathrm{C}$. It can be seen that both glass fibre types reduce in strength, with the silane sized glass falling by a greater percentage of its original strength. The water sized fibres exhibit a fairly linear reduction in room temperature strength with increasing conditioning temperature. The strength of silane-sized glass appears relatively stable at low temperatures but exhibits a threshold (at approximately $250^{\circ} \mathrm{C}$ ) above which a precipitous reduction in fibre 
strength and strain to failure occurs. These results appear to agree well with results from other investigators [8-12]. Consequently it appears that the average strength of glass fibres is strongly influenced by thermal conditioning at temperatures and times which may commonly be experienced during the thermal processing of end-of-life composite materials in order to obtained recycled fibres [7]. These effects appear to be occurring at temperatures significantly lower than the $1150-1250^{\circ} \mathrm{C}$ temperature range for the manufacture of glass fibre and also well below $759^{\circ} \mathrm{C}$ the glass transition temperature of boron free E-glass [19].

Further important conclusions that can be drawn from Figures 2 and 3 include the clear role of sizing in protecting the strength levels in glass fibres. It seems likely that the degradation and consequent loss of protection, during thermal conditioning, of the organic part of the polysiloxane layer on the fibre surface, very likely contributes to the loss of average fibre strength in the silane sized fibres. However, since the water sized fibres also exhibit a strength reduction after elevated temperature conditioning it seems probable that there also exists a strength reduction mechanism related to a fundamental change in the glass itself. This conclusion is supported by the results of a deeper investigation of the relationship between the strength of thermally conditioned glass fibres and the degradation of the silane coating which has recently been reported [18].

It is well known that the commonly used method to determine single fibre modulus delivers results that are directly dependent on the gauge length tested. The modulus dependence on gauge length is a phenomenon related to the use of the testing machine crosshead position to approximate the fibre strain that does not take into account the contribution of the strain of the other components in the testing system. All modulus values reported here have been corrected for the test system compliance using a value 
of $0.0346 \mathrm{~mm} / \mathrm{GPa}$, obtained from Figure 4 using data from a recently reported gauge length study of the same fibres [16]. The results for the average room temperature fibre modulus (error bars show 95\% confidence limits) of unsized and silane sized glass fibres are shown as a function of the sample conditioning temperature in Figure 5. It can be seen that both samples show a significant trend for room temperature modulus being increased by a short elevated temperature conditioning. It is also clear in Figure 5 that both samples show an approximately linear increase in room temperature modulus with conditioning temperature above approximately $200^{\circ} \mathrm{C}$. Furthermore, although both samples started with approximately the same level of tensile modulus, the modulus of the water sized fibres was found to be significantly higher (at $95 \%$ confidence level) than that of the silane coated fibres after elevated temperature conditioning. Hence it appears that the silane coating impedes the mechanism that leads to an increase in modulus of the fibres during the hot conditioning. Results for the unconditioned fibre modulus for both samples from a previous investigation measured approximately 20 months prior to the current measurements are also presented in Figure 5. It is noted that the modulus values for both fibre samples are significantly lower in this investigation.

\subsection{Discussion of fibre strength results}

Data from single fibre strength measurement are commonly subjected to further detailed analysis using Weibull methods [20]. These details of the Weibull method are well documented and will not be reproduced here $[17,20]$. In some cases, experimental single fibre tensile strength data can be well described using a two parameter unimodal Weibull analysis. However, curvature in the Weibull plot of experimental single fibre data is frequently observed at low strength values [17]. A recent study has demonstrated that this deviation can be well explained by the existence of an experimental lower strength limit $\left(\sigma_{\mathrm{T}}\right)$ below which the fibre is not strong enough to survive the pretest 
sample preparation and handling [17]. Consequently, the lowest strength values of the estimated Weibull distribution do not appear in the experimental data. In such cases it is necessary to revert to the original three parameter form of Weibull distribution [17]. Unfortunately this phenomenon seriously complicates attempts to use Weibull analysis of single fibre strength data to distil useful information about the materials science of the tested single fibres. The experimentally reflected lower strength limit is operator sensitive, sample preparation dependent, and test procedure dependent as well as being related to the material properties. Consequently, although average values for $\sigma_{\mathrm{T}}$ can be obtained, the value of $\sigma_{\mathrm{T}}$ is not a constant parameter but can be different for each individual fibre test. This situation can become even more complex when further structure is observed in a Weibull plot, often interpreted as evidence for multiple flaw populations in the fibres under test $[12,16,17]$. This is frequently observed in the distribution of strength from sized glass and carbon fibres and analysis using different forms of bimodal Weibull strength distribution has been attempted. Thomason et al recently presented data on the APS sized fibres used in this investigation indicating that the partially concurrent bimodal Weibull distribution gave the most realistic model for these results [12].

Typical examples are presented in Figure 6 which shows Weibull plots of the strength data for the APS fibres before heat conditioning and for the water-sized fibres after heat conditioning at $600^{\circ} \mathrm{C}$. This covers the full range of behaviour observed in Weibull analysis of the data from all fibres and conditions as all sample strength data produced Weibull plots similar in form to one of these two examples. At higher strength values the data for the $600^{\circ} \mathrm{C}$ conditioned fibres mainly follow a linear relationship typical of a unimodal flaw distribution. However, at lower strengths the data exhibit a downward deviation in curvature that is a symptom of the experimental inability to access very low 
strength values as discussed above. Consequently the data are poorly fitted by a straight line (indicative of the simplest two parameter Weibull distribution) but can be well fitted, as shown, by a more general three parameter Weibull distribution. Nevertheless, it has been shown that it is actually more accurate to fit the data with a two-parameter model where the calculated values below the lower experimental limit $\sigma_{\mathrm{L}}$ have been removed [17]. The data for the APS sized fibres without any heat conditioning exhibited a more complex fibre strength distribution and appear to exhibit three distinct regions in Figure 6. This could be interpreted as indicating that the failure of silane coated glass fibres is controlled by two, or more, distinct types of flaw population. The overall failure distribution is then the result of the interaction of these flaw populations, which may be described by the multimodal Weibull distribution and precludes the use of the simple linear fitting to obtain the Weibull parameters. It is possible to fit the results for the APS sized fibres using a partially concurrent bimodal Weibull distribution [12] where the lower strength part of the distribution also includes a nonzero value of $\sigma_{\mathrm{T}}$. However, it bears commenting that this requires the reliable estimation of six adjustable parameters. Although further discussion and analysis of all fibre strength data is certainly possible, one has to question whether all of the experimental and theoretical uncertainties discussed above warrant any attempts at interpretation of this type of Weibull analysis in terms of real material parameters.

A more robust analysis method that requires a less complex theoretical background is simply to plot the cumulative probability of fibre failure $\left(\mathrm{P}_{\mathrm{F}}\right)$ as a function of fibre strength as shown in Figures 7 and 8 for the two fibre types in this investigation. Figure 7 shows the data for the water sized fibres. It can be observed that there is considerable separation between the unsized fibres conditioned above $300^{\circ} \mathrm{C}$ and the as-received fibres. The region between these two groups appears to be spanned by the distribution 
for the fibres conditioned at $250^{\circ} \mathrm{C}$. It can also be observed that all the heat conditioned fibres have a similar low strength distribution for the first $25-30 \%$ of the distribution. One possible explanation for these observations is that the low strength region of fibre strength of the heat conditioned fibres is a result of further mechanical damage to the unsized fibres caused by the handling of the fibres in the process of heat conditioning. The strength of any stronger water-sized fibres is then also reduced in greater degree with increasing heat conditioning temperature possibly indicating the presence of some temperature dependent structural change in these fibres $[12,18,19]$.

In the case of the APS sized fibres the data in Figure 8 indicate somewhat different trends in PF. The as received fibres show a broad strength distribution that appears to be split approximately 50:50 in low and high strength regions. Initially heat conditioning appears to affect the high strength part of this distribution, shifting it to lower values with increasing heat conditioning from $250^{\circ} \mathrm{C}$ to $380^{\circ} \mathrm{C}$. The lowest $30 \%$ of these three distributions appear to be unaffected. Heat conditioning at $450^{\circ} \mathrm{C}$ and above, appears to shift all fibres to lower strengths and removes the appearance of bimodality. Building on the discussion of the water sized fibre results this could be interpreted as indicating that the APS coating protects the fibres from the possibility of mechanical damage during the handling of the fibres in the process of heat conditioning. Consequently there is no reduction in strength of the fibres in the low strength region of the distribution. Nevertheless, heat conditioning will degrade the organic part of the silane coating $[10,12,18]$. It seems likely that the high strength fraction of the fibres are initially well protected by the silane and so it is the high strength fraction of the distribution that is initially affected by the thermal conditioning at lower $\left(250-380^{\circ} \mathrm{C}\right)$ temperatures. At $450^{\circ} \mathrm{C}$ and above it has been shown that the organic part of the silane is fully degraded resulting in a further reduction in the strength of the high strength fibres [18]. It can also 
be supposed that the temperature dependent structural effects observed with the water sized fibre data will also increasingly affect the results for the APS sized fibres conditioned at increasingly higher temperatures.

\subsection{Influence of chemical post-treatment on the glass fibre strength}

The effects of various chemical post-treatments on the strength of $450{ }^{\circ} \mathrm{C}$ heatconditioned glass fibres are summarised in the Table 2. Direct silanisation with either a single silane (APS or GPS) or the APS:SPS silane blend did not result in any significant increase in the average fibre strength of heat-treated fibres. The expectation for restoring fibre strength through simple silanisation originated from the critical role that silane coupling agents play in the manufacture of glass fibre reinforcements. It is well known that these silanes have the ability to help maintain fibre strength [16]. It has been recently demonstrated that strength retention caused by silane deposition on glass fibres during manufacture can be explained from surface protection viewpoint [16]. However, it has also been suggested by some authors that silanes can 'heal' surface flaws by patching the crack tips, mitigating stress concentration during loading $[21,22]$. It is reasonable to suggest that polysiloxane bonds with high cross-link density need to be formed between deposited silane molecules and the glass surface if any significant effect is to be achieved through such a healing mechanism. One of possibilities for the failure of direct silanisation in strength regeneration of the heat-treated glass fibre may be the deactivation of glass surface by exposure to elevated temperatures. It has been shown with both amorphous silica and glass fibre that severe dehydration can occur when subjected to thermal treatment above $400^{\circ} \mathrm{C}$ in air $[23,24]$. While it has been suggested that complete rehydration of such calcinated surfaces may be very difficult, it has been reported that acid treatment with $\mathrm{HCl}$ can successfully restore hydroxyl groups on the surface of glass fibre heat-treated at $450{ }^{\circ} \mathrm{C}[24,25]$. In the present work, we also attempted this acid reactivation of the fibre surface prior to a further attempt at 
silanisation. The results in Table 2 indicate that $\mathrm{HCl}$ treatment itself does not significantly change the strength of heat-treated fibres and a similar lack of significant changes was found for samples silanised after the acid reactivation treatment, as shown by samples G-K. Several possible explanations exist which may account for this lack of strength improvement. Although it has been reported that E-glass fibre calcinated at $450{ }^{\circ} \mathrm{C}$ can be reactivated with a significant increase of surface silanol groups using acidic conditions, the number of silanol groups may be still insufficient to form a tight network in the vicinity of the critical flaws. In fact, one may well question whether such a strong flaw repair patch could ever be formed with relatively large silane molecules. Other possibilities may be associated with compositional change in the glass fibre surface. Both thermal conditioning and acid treatment have the potential to significantly change surface composition, which may then change the reactivity with the silanes in comparison to the surface of pristine glass fibre. To further investigate these possibilities, similar chemical treatments were applied to the unsized glass fibres without prior heat conditioning. The results for these chemically treated fibres listed in Table 3 also indicate only minor effects of acid and/or silane treatment on the strength of unsized fibres that had no received thermal conditioning whatsoever. The results presented in Table 2 and 3 raise further doubts on the validity of the flaw healing theory but more importantly indicate that further work is needed to improve understanding of the role of post-silanisation in the strength of glass fibres.

\subsection{Discussion of fibre modulus results}

Although the reduction of room temperature glass fibre strength due to an elevated temperature conditioning has been observed and reported by a number of authors, there has been much less discussion of the effects on the fibre modulus. Feih et al observed similar strength losses in heat conditioned E-glass fibres as reported here. However they 
reported no significant change in the modulus of their fibres [10]. Kennerley et al also reported no apparent change in the modulus of E-glass fibres recycled out of GRP at temperatures from $450-600^{\circ} \mathrm{C}[26]$. However, Otto at Owens Corning reported that the modulus of E-glass fibre [27] at room temperature increased systematically from 75 GPa up to $86 \mathrm{GPa}$ after conditioning for four hours at a temperature of $600{ }^{\circ} \mathrm{C}$. This was related to changes in the density of the glass due to densification during conditioning. Glass fibre density is lower than that of bulk glass as a result of the high rate of cooling during manufacture. However, when the fibre is subjected to elevated temperatures, the physical properties tend to return to those values representative of the massive, annealed form of the glass resulting in a related increase in the modulus. More recently, in another paper from Owens Corning, Korwin-Edson et al also reported room temperature density and modulus increases in glass fibres conditioned for one hour at temperatures from $100^{\circ} \mathrm{C}$ to $900^{\circ} \mathrm{C}$ [11]. Their investigation covered a range of fibres made from different glass formulations (including the Advantex formulation used in this study). They reported that, after an initial dip in modulus to a minimum at a conditioning temperature of $100^{\circ} \mathrm{C}$, the modulus of heat conditioned H-glass fibre increased with increasing conditioning temperature due to structural changes and densification of the glass network. However they also mentioned the possible role of surface and bulk water in the glass in connection with the glass fibre modulus.

In Figure 9 we compare our results on the change of fibre modulus as a function of conditioning temperature with those of Otto and Korwin-Edson et al. To remove absolute differences caused by differences in glass fibre formulation the modulus data are normalised to the room temperature unconditioned results. It is interesting to note that, in comparison to Korwin-Edson's results, Otto did not obtain an initial drop in fibre modulus with low temperature conditioning and recorded a much larger relative 
increase in modulus at higher conditioning temperatures. In the case of our results it appears that the uncoated fibre results agree well with those of Otto whereas the results for the APS coated fibres appear to match those of Korwin-Edson et al with an initial drop in modulus. In a recent paper, Yang and Thomason discussed the novel use of a thermo-mechanical analyser to simultaneously measure the thermal expansion coefficient, densification, modulus of single glass fibres (the same APS coated fibres used in this investigation) and also to thermally condition and measure room temperature modulus in the same instrument [19]. Their results for room temperature modulus as a function of conditioning temperature (for 30 minutes) are also compared in Figure 9. These data appear to show all the above discussed features with an initial drop in modulus at low conditioning temperatures and then a rapid increase in modulus with conditioning above $300^{\circ} \mathrm{C}$. They suggested that these observations could be explained by a combination of structural relaxation in the glass fibre combined with desorption of water from within the fibre [19]. Water can be present in significant quantities in glass and can act as plasticiser. Removal of the water from the network may stiffen the structure and contribute to the increase of the fibre modulus.

Glasses manufactured using standard melt technologies always contain residual water. [28]. Water can exist in, and diffuse through, glass as both molecular water $\left(\mathrm{H}_{2} \mathrm{O}\right)$ and hydroxyl $(\mathrm{OH})$. The mobile species, molecular water, can diffuse into and react with the silica to produce immobile hydroxyl by the reaction $\mathrm{H}_{2} \mathrm{O}+\equiv \mathrm{Si}-\mathrm{O}-\mathrm{Si} \equiv \Leftrightarrow 2 \equiv \mathrm{Si}-\mathrm{OH}$. It is noteworthy that this reaction breaks structural bonds, which must have consequences on the response of the glass structure to applied stress. At high enough temperatures, the reaction is fast and reaction equilibrium is established with an equilibrium constant, $\mathrm{K}=$ $[\mathrm{OH}]^{2} /[\mathrm{H} 2 \mathrm{O}]$, where $[\mathrm{OH}]$ and $[\mathrm{H} 2 \mathrm{O}]$ are the concentrations of hydroxyl and molecular water respectively [29]. The concentration of dissolved molecular water, [H2O], in the 
glass is proportional to atmospheric water vapour pressure. Mechanical loss increases and modulus decreases with increasing water content in glass [30,31]. Tomozawa has suggested that water enters into glasses, accelerated by tensile stress, and causes swelling which reduces modulus and strength in a manner similar to the plasticization effect in polymers $[29,30]$. It is interesting to note that the maximum values obtained by thermal conditioning at $600^{\circ} \mathrm{C}$ in Figure 5 are approximately equal to the values obtained for the unconditioned fibres two years earlier [16]. This could imply that it is not so much that the glass fibre modulus was increased by thermal conditioning, but that the moduli of the unconditioned fibres measured in this investigation were lower than expected. The thermal conditioning of the fibre then reversed this time dependent loss of modulus most likely by removal of "plasticizing" water. Furthermore, the magnitude of $\mathrm{K}$ has been shown to increase in the temperature range $200-550^{\circ} \mathrm{C}$ in silica glass [32] implying the likelihood of increasing Si-O-Si structural bond breakage with increasing conditioning temperature in the temperature range of this investigation.

Many researchers engaged in elucidating the complex structure-performance relationships in composite materials operate under an initial assumption that the modulus of inorganic reinforcement fibres is fixed and invariable. Consequently the source of environmentally driven composite performance changes is often sought in the polymer matrix or the fibre-matrix interface. These results bring up the interesting possibility that long-term exposure of glass fibres to an uncontrolled humid environment may result in a significant reduction of fibre modulus. Since the fibres used in this investigation have also been the subject of a number of other projects it is possible to examine the room temperature modulus of these fibres over a period of approximately five years since their production. These results are shown in Figure 10 as a plot of average modulus versus Log (time). There is some scatter in the data, possibly 
due the uncontrolled storage environment and to the large number of different investigators involved in the generation of the data over this long time period. Nevertheless, there is a clear trend visible in the data showing a time dependent lowering of the fibre modulus of both the water sized and silane sized glass fibres. Figure 10 also shows the expected value of fibre modulus for these samples after 10 and 25 years. At 25 years the fibre modulus could be below $62 \mathrm{GPa}$, which is more than $20 \%$ reduction from the initial modulus of an Advantex glass fibre. If this phenomenon is associated with slow moisture diffusion into the glass fibres then clearly one might expect an acceleration of the effect at higher temperature and humidity. Consequently, we consider that this effect could be of great importance for the long term performance of glass fibres (and their composites) in humid environments such as offshore wind turbine blades, or the short term performance of glass fibres (and composites) that experience hot-wet conditions such as composites used in automotive cooling systems. Clearly these considerations merit further controlled investigations and we have initiated a dedicated study of time-dependent changes in the modulus of E-glass fibres stored in controlled environments. This will be reported at a later stage.

\section{Conclusions}

The results of single fibre tensile testing presented here clearly show that the thermal history likely to be encountered by glass fibres recycled out of end-of-life composite by processing in the $250-600^{\circ} \mathrm{C}$ temperature range can potentially cause dramatic lowering of the room temperature fibre strength and strain at failure. The average room temperature single fibre tensile strength of water sized and silane sized E-glass fibres was decreased by up to $70 \%$ by only 15 minutes conditioning at $600^{\circ} \mathrm{C}$. Silane sized fibres exhibited a much higher initial strength than water sized fibres due to the protective influence of the silane surface coating. Silane sized fibres also exhibited 
relative stability in average tensile strength up to $250^{\circ} \mathrm{C}$. However, conditioning above this temperature resulted in a precipitous drop in room temperature strength. The water sized fibres exhibited an approximately linear decrease in average room temperature tensile strength with increasing conditioning temperature.

Further analysis of the single fibre strength distributions using Weibull methods indicated that the strength distribution of the water sized fibres could be well represented by a unimodal, three-parameter, Weibull distribution which included the lower strength limit imposed by the minimum fibre strength required in order to be able to prepare a test sample. The strength distributions of the sized fibres were more complicated and required the use of a partially concurrent bimodal Weibull distribution. However, the use of a simple analysis of the cumulative fibre strength probability resulted in more useful material science understanding than the Weibull analysis. The observed loss in fibre strength was attributed, in part, to the thermal degradation of the organic part of the silane coating and the consequential increase in sensitivity to fibre surface mechanical and environmental damage. Nevertheless, the parallel changes in strength of the uncoated fibres may imply that there are also other changes taking place in the glass fibre structure at these relatively low processing temperatures.

Fibre strength regeneration was investigated using acid surface activation and postsilanisation of the heat-treated glass fibres. Little significant change in fibre strength was observed for a range of acid and silane post-treatments of heat conditioned fibres. Several possibile explanations were discussed including the density of surface hydroxyl groups and potential changes in the fibre surface composition. These aspects were further investigated through silanisation of unsized glass fibres. The initial results suggest that recoating glass fibres with typical silanes may not be an attractive route to 
regenerating the value of heat conditioned glass fibres. More work is required to further investigate the potential of post-silanisation in strength regeneration of thermally recycled glass fibres. In contrast to the fibre strength, the fibre modulus was found to increase with increasing thermal conditioning temperature. This was discussed in terms of the possible effects of absorbed water on fibre properties. It was found that the modulus of these fibre decrease logarithmically as a function of age. It was suggested observed that this effect could be of significance for the long-term performance of glass fibres reinforced composites.

\section{Acknowledgement}

The authors would like to thank Owens Corning-Vetrotex for providing the glass fibres used in this study. The authors would also like to acknowledge the financial support from Engineering and Physical Sciences Research Council under the ReCoVeR and TARF-LCV projects and the assistance of the Advanced Materials Research Laboratory of the University of Strathclyde with the mechanical testing.

\section{References}

[1] Job S. Recycling glass fibre reinforced composites - history and progress. Reinforced Plastics 2013;57(5):19-23.

[2] Technology Needs To Support Advanced Composites in the UK. Written by The InterAgency Composites Group. Department for Business, Innovation \& Skills. November 2009. (www.bis.gov.uk).

[3] Red C. Wind turbine blades: Big and getting bigger. Composites World June 2008. http://www.compositesworld.com/articles/wind-turbine-blades-big-and-gettingbigger

[4] Larsen K. Recycling wind. Reinforced Plastics, 2009;53:20-25.

[5] Williams PT, Cunliffe A, Jones N. Recovery of value-added products from the pyrolytic recycling of glass-fibre composite waste. J Energy Inst 2005;78:51-61.

[6] Oliveux G, Bailleul JL, Salle ELGL. Chemical recycling of glass fibre reinforced composites using subcritical water. Compos Pt A 2012;43(11):1809-1818.

[7] Pickering SJ. Recycling technologies for thermoset composite materials-current status. Compos Pt A 2006;37:1206-1215.

[8] Thomas WF. An investigation of the factors likely to affect the strength and properties of glass fibres. Physics and Chemistry of Glasses 1960;1:4-18.

[9] Feih S, Manatpon K, Mathys Z, Gibson AG, Mouritz AP. Strength degradation of glass fibers at high temperatures. J Mater Sci 2009:44:392-400. 
[10] Feih S, Boiocchi E, Mathys G, Gibson AG, Mouritz AP. Mechanical properties of thermally-treated and recycled glass fibres. Compos Pt B 2011;42(3):350-358.

[11] Korwin-Edson ML, Hofmann DS, McGinnis PB. Strength of High Performance Glass Reinforcement Fiber. Int J Applied Glass Science 2012;3(2):107-121

[12] Thomason JL, Kao CC, Ure J, Yang L. The strength of glass fibre reinforcement after exposure to elevated composite processing temperatures. Accepted J Mater Sci September 2013.

[13] Piggott MR, Yokom JC. The weakening of silica fibres by heat treatment. Glass technology. 1968;9:172-175.

[14] Militký J, Kovačič V, Rubnerová J. Influence of thermal treatment on tensile failure of basalt fibers. Engineering Fracture Mechanics 2002;69:1025-1033.

[15] Thomason JL. The influence of fibre properties of the performance of glassfibre-reinforced polyamide 6,6. Compos Sci Tech 1999;59(16):2315-2328.

[16] Yang L, Thomason JL. Effect of Silane Coupling Agent On Mechanical Performance Of Glass Fibre. J Mater Sci 2013;48:1947-1954.

[17] Thomason JL. On the Application of Weibull Analysis to Experimentally Determined Single Fibre Strength Distributions. Compos Sci Tech 2013;77:74-80.

[18] Jenkins PG, Yang L, Liggat JJ, Thomason JL. Investigation of the strength loss of E-glass fibres after thermal conditioning. Submitted Compos Sci Tech.

[19] Yang L, Thomason JL. The Thermal Behaviour of Glass Fibre Investigated By Thermomechanical Analysis. J Mater Sci 2013;48:5768-5775.

[20] Weibull W. A statistical distribution function of wide applicability. Journal of Applied Mechanics 1951;18:293-297.

[21] Zinck P, Pay MF, Rezakhanlou R, Gerard JF. Mechanical characterisation of glass fibres as an indirect analysis of the effect of surface treatment. J Mater Sci 1999;34:2121-2133.

[22] Feih S, Thraner A, Lilholt H. Tensile strength and fracture surface characterisation of sized and unsized glass fibers. J Mater Sci 2005;40:1615-1623.

[23] Zhuravlev LT. The surface chemistry of amorphous silica. Colloids and Surfaces A 2000;173:1-38.

[24] González-Benito J, Baselga J, Aznar AJ. Microstructural and wettability study of surface pretreated glass fibres. J Mater Process Technol 1999;92-93:129-134.

[25] Sever K, Seki Y, Tavman IH, Erkan G, Cecen V. The structure of $\gamma$ glycidoxypropyltrimethoxysilane on glass fiber surfaces: Characterization by FTIR, SEM, and contact angle measurements. Polymer Composites. 2009;30(5):550-558.

[26] Kennerley JR, Kelly RM, Pickering SJ, Rudd CD. Characterisation and Reuse of Glass Fibres Recycled from Scrap Composites by a Fluidised Bed Process. Compos Pt A, 1998:29;839-845.

[27] Otto WH. Compaction Effects in Glass Fibers. J Am Cer Soc 1961;44(2):68-72.

[28] Naraev VN. The Influence of Water on the Glass Properties. Glass Physics and Chemistry, 2004;30(5):367-389.

[29] Lezzi PJ, Xiao QR, Tomozawa M, Blanchet TA, Kurkjian CR. Strength increase of silica glass fibers by surface stress relaxation. J Non-Cryst Solids 2013;379:95-106.

[30] Ito S, Tomozawa M. Dynamic Fatigue of Sodium-Silicate Glasses with High Water Content. Journal de Physique 1982;C9:611-614.

[31] Day DE, Stevels JM. Effect of dissolved water on the internal friction of glass. J Non-Cryst Solids 1974;14(1):165-177.

[32] Tomozawa M, Kim DL, Agarwal A, Davis KM. Water diffusion and surface structural relaxation of silica glasses. J Non-Cryst Solids 2001;288:73-80. 


\begin{tabular}{lcc}
\hline & Unsized & APS Sized \\
\hline Average Diameter $[\mu \mathrm{m}]$ & 18.18 & 17.61 \\
Standard Deviation $[\mu \mathrm{m}]$ & 1.28 & 1.53 \\
Number of fibres & 537 & 719 \\
Confidence Level $(95.0 \%)$ & 0.11 & 0.11 \\
Minimum Diameter $[\mu \mathrm{m}]$ & 15.05 & 13.88 \\
Maximum Diameter $[\mu \mathrm{m}]$ & 23.06 & 23.52 \\
\hline
\end{tabular}

Table 1: Fibre diameter analysis

\begin{tabular}{ccccc}
\hline Sample & $\begin{array}{c}\text { Duration of acid } \\
\text { treatment }(\mathrm{h})\end{array}$ & Silane type & $\begin{array}{c}\text { Ave. tensile } \\
\text { strength }(\mathrm{GPa})\end{array}$ & $\begin{array}{c}\text { 95\% Confidence } \\
\text { Limit }\end{array}$ \\
\hline A & 0 & - & 0.68 & 0.05 \\
B & 0 & APS & 0.86 & 0.07 \\
C & 0 & GPS & 0.73 & 0.08 \\
D & 0 & APS:SPS & 0.64 & 0.05 \\
E & 1 & - & 0.58 & 0.04 \\
F & 2 & - & 0.74 & 0.04 \\
G & 1 & APS & 0.75 & 0.05 \\
H & 2 & APS & 0.74 & 0.04 \\
I & 1 & GPS & 0.8 & 0.06 \\
J & 2 & GPS & 0.79 & 0.05 \\
K & 1 & APS:SPS & 0.81 & 0.04 \\
\hline
\end{tabular}

Table 2: The effect of chemical treatments on the strength of $450^{\circ} \mathrm{C}$ conditioned glass fibre

\begin{tabular}{ccccc}
\hline Sample & $\begin{array}{c}\text { Duration of acid } \\
\text { treatment }(\mathrm{h})\end{array}$ & Silane type & $\begin{array}{c}\text { Ave. tensile } \\
\text { strength }(\mathrm{GPa})\end{array}$ & $\begin{array}{c}\text { 95\% Confidence } \\
\text { limit }\end{array}$ \\
\hline $\mathrm{L}$ & 0 & - & 1.34 & 0.16 \\
$\mathrm{M}$ & 0 & APS & 1.55 & 0.17 \\
$\mathrm{~N}$ & 0 & APS:SPS & 1.38 & 0.20 \\
$\mathrm{O}$ & 1 & - & 1.34 & 0.21 \\
$\mathrm{P}$ & 1 & APS & 1.52 & 0.16 \\
$\mathrm{Q}$ & 1 & APS:SPS & 1.56 & 0.14 \\
\hline
\end{tabular}

Table 3: The effect of chemical treatments on the strength of unsized glass fibres 

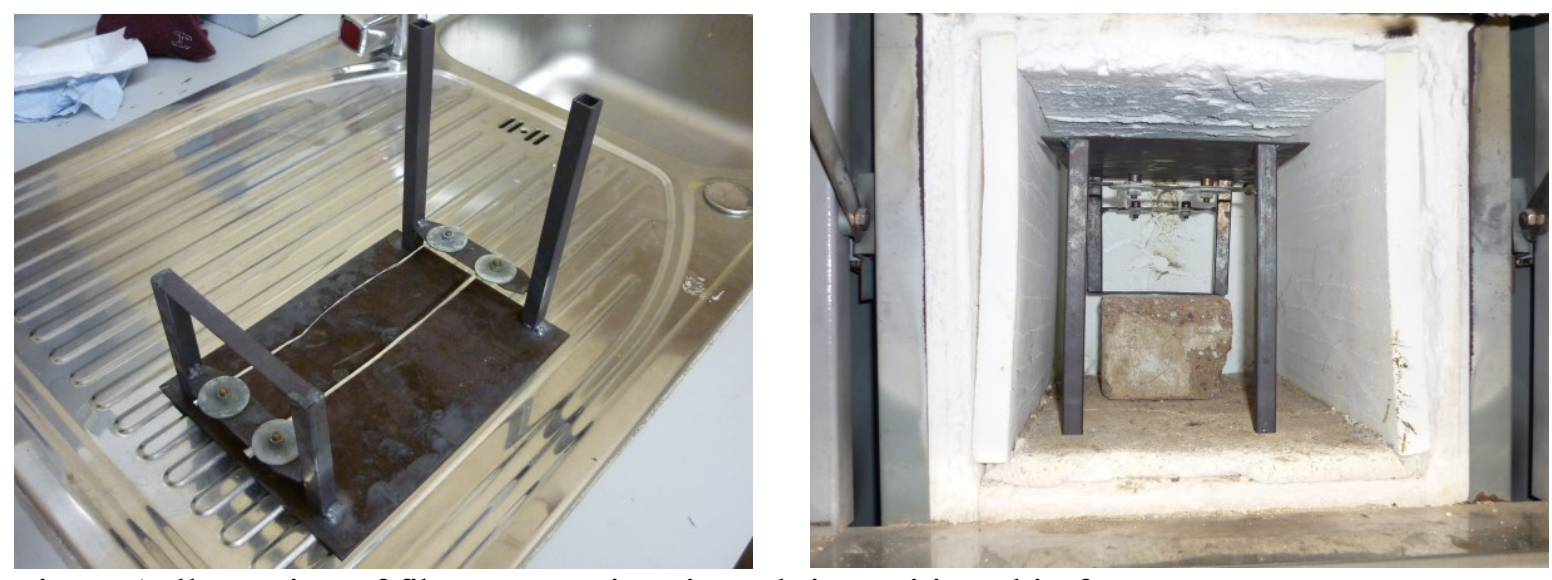

Figure 1 Illustration of fibre suspension rig and rig positioned in furnace

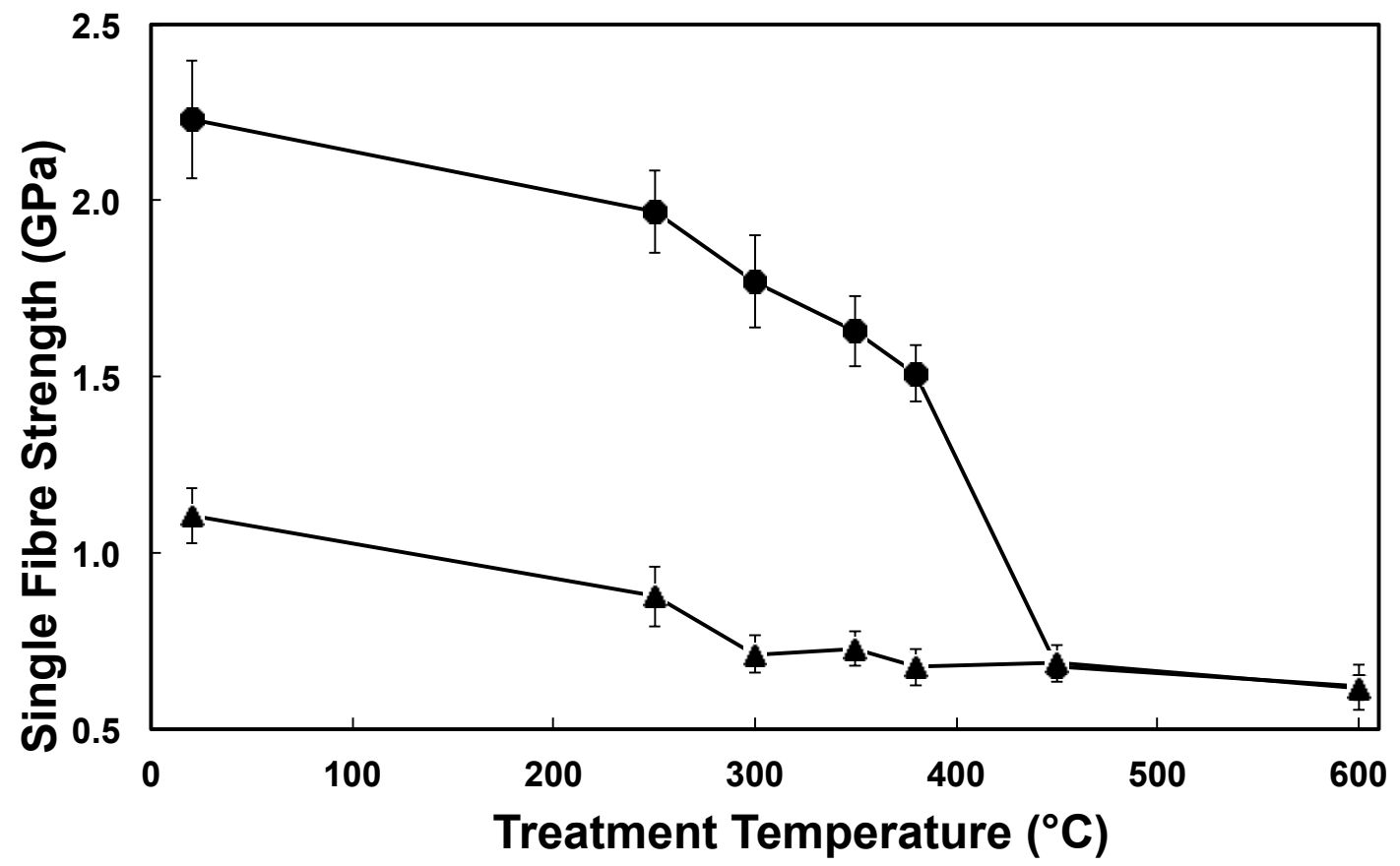

Figure 2 Influence of heat treatment temperature on room temperature glass fibre average strength ( $\boldsymbol{\Delta}$ water sized, $\bullet$ APS sized). 


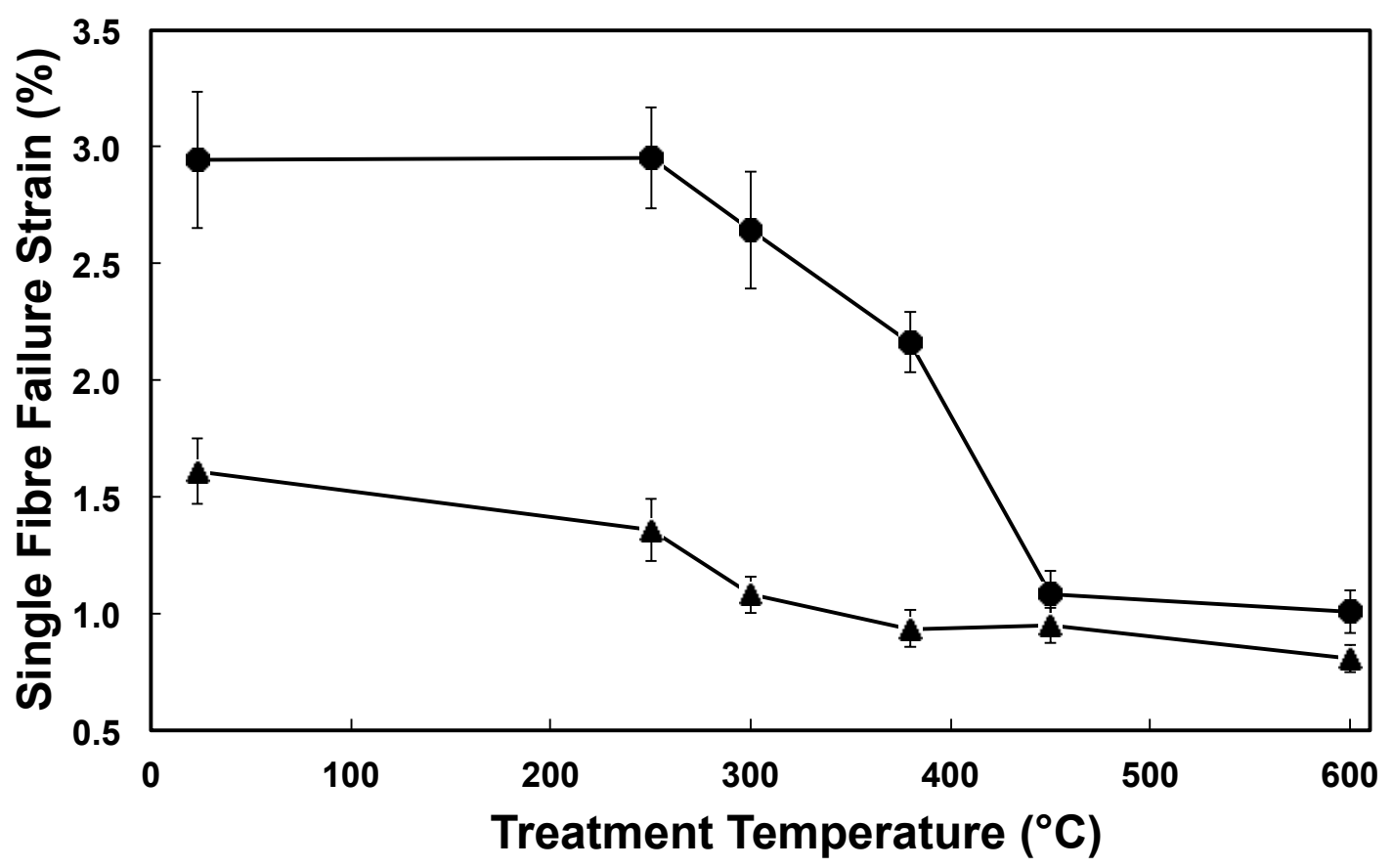

Figure 3 Influence of heat treatment temperature on room temperature glass fibre average failure strain ( $\boldsymbol{\Delta}$ water sized, $\bullet$ APS sized).

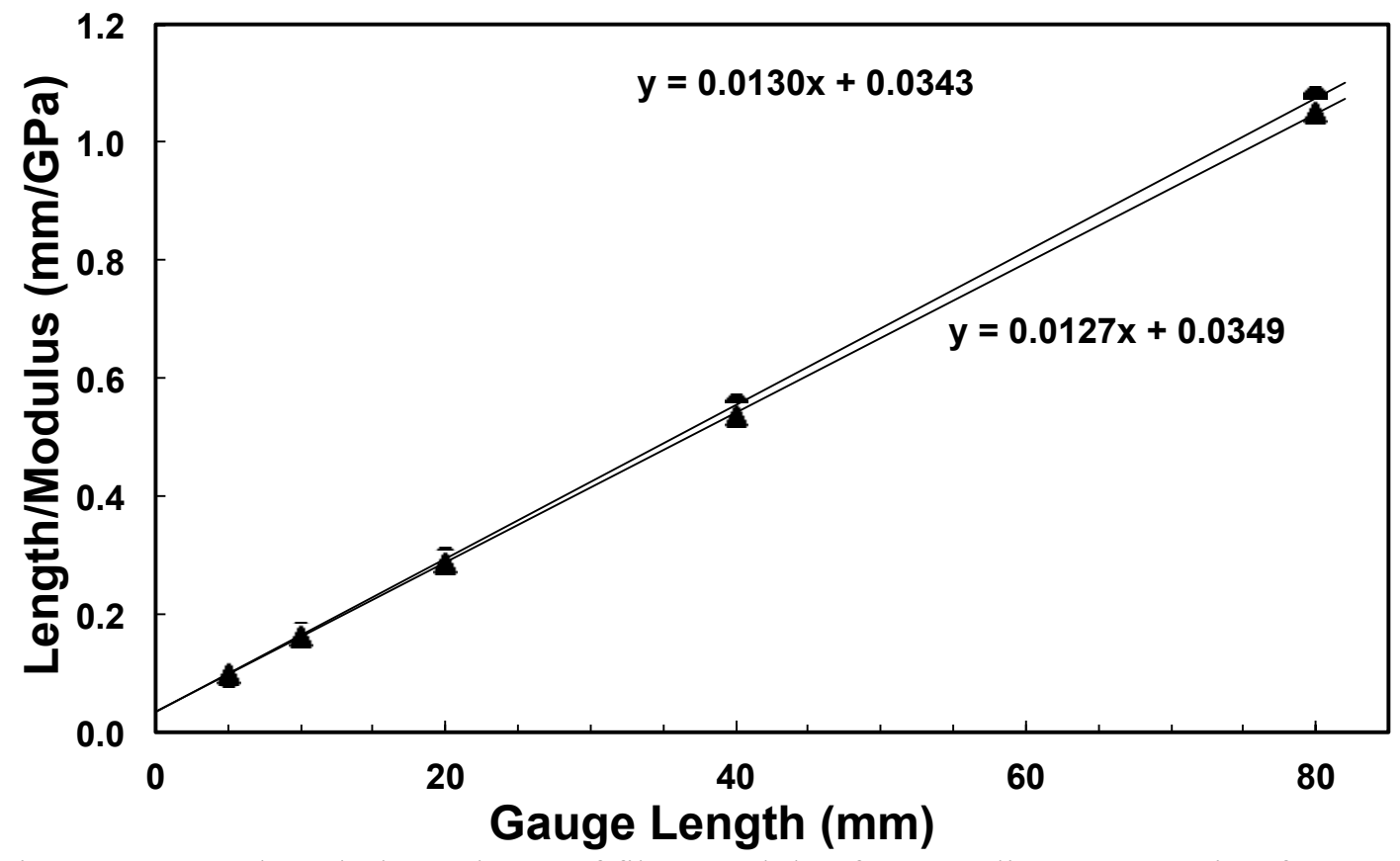

Figure 4 Gauge length dependence of fibre modulus for compliance correction factor ( $\boldsymbol{\Lambda}$ water sized, $\bullet$ APS sized). 


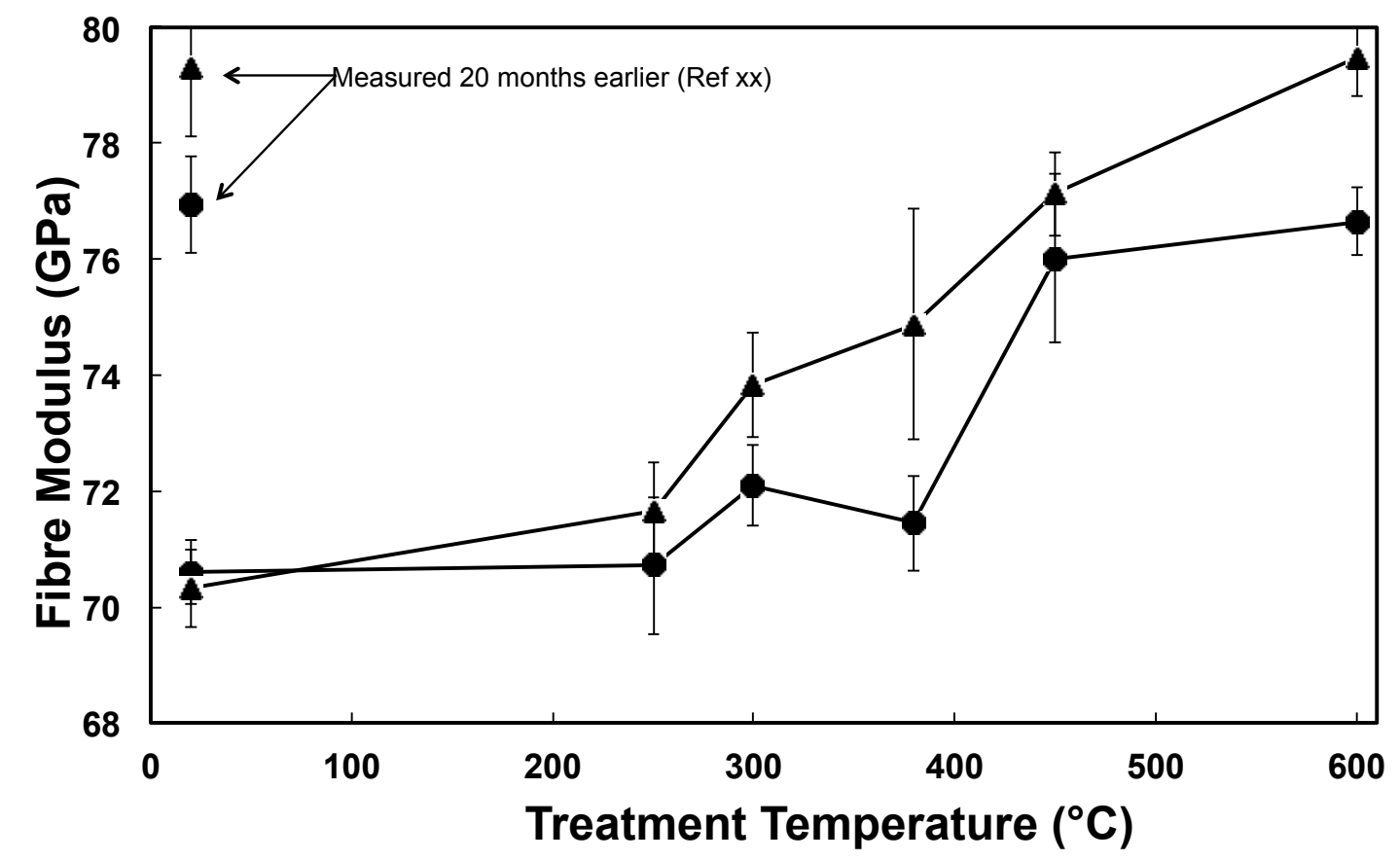

Figure 5 Influence of heat treatment temperature on room temperature glass fibre average modulus ( $\boldsymbol{\Delta}$ water sized, $\bullet$ APS sized).

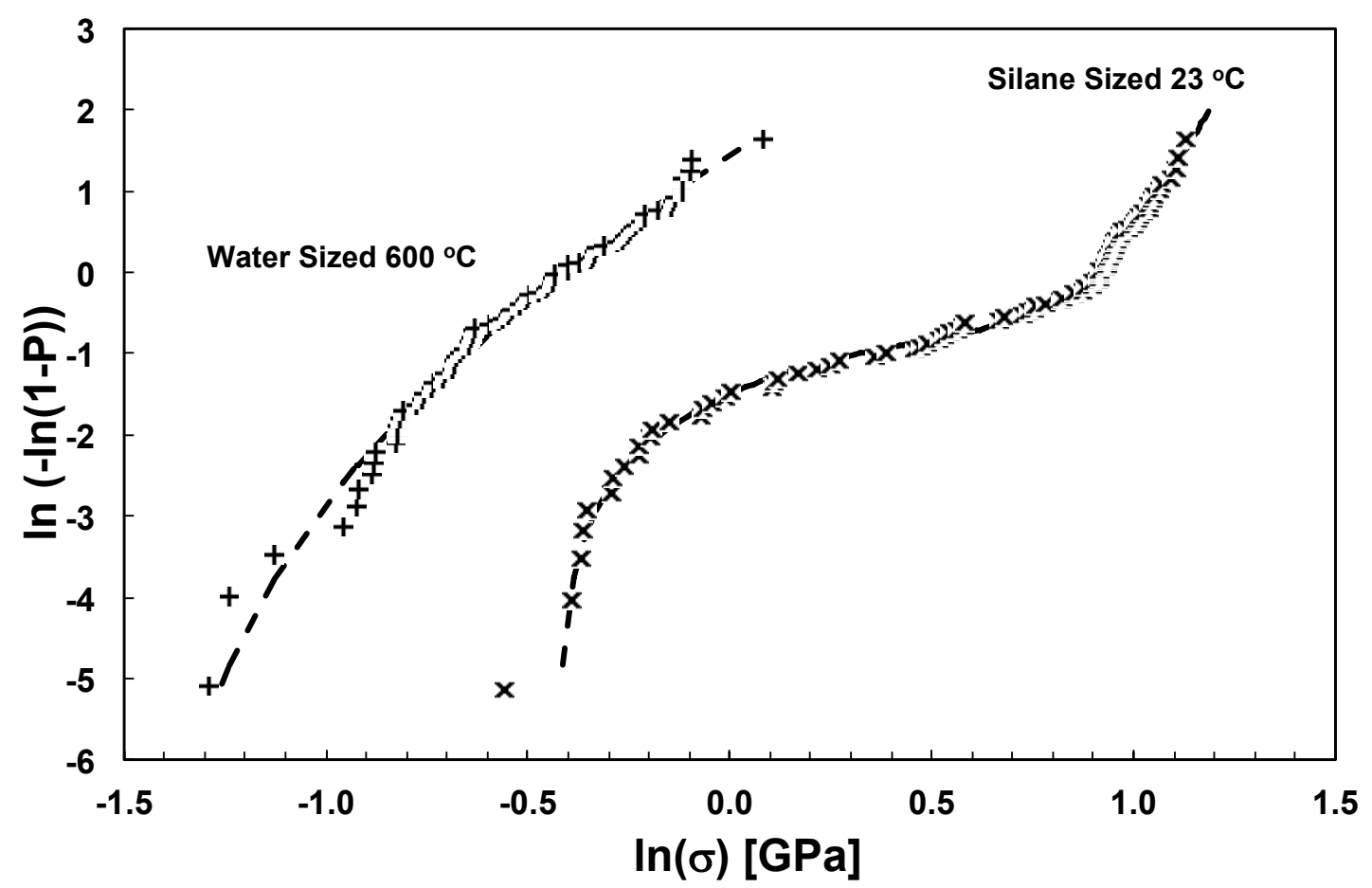

Figure 6 Weibull plot of single fibre strength (+ water sized fibres after $600^{\circ} \mathrm{C}$ conditioning, $\times$ unconditioned APS sized fibres 


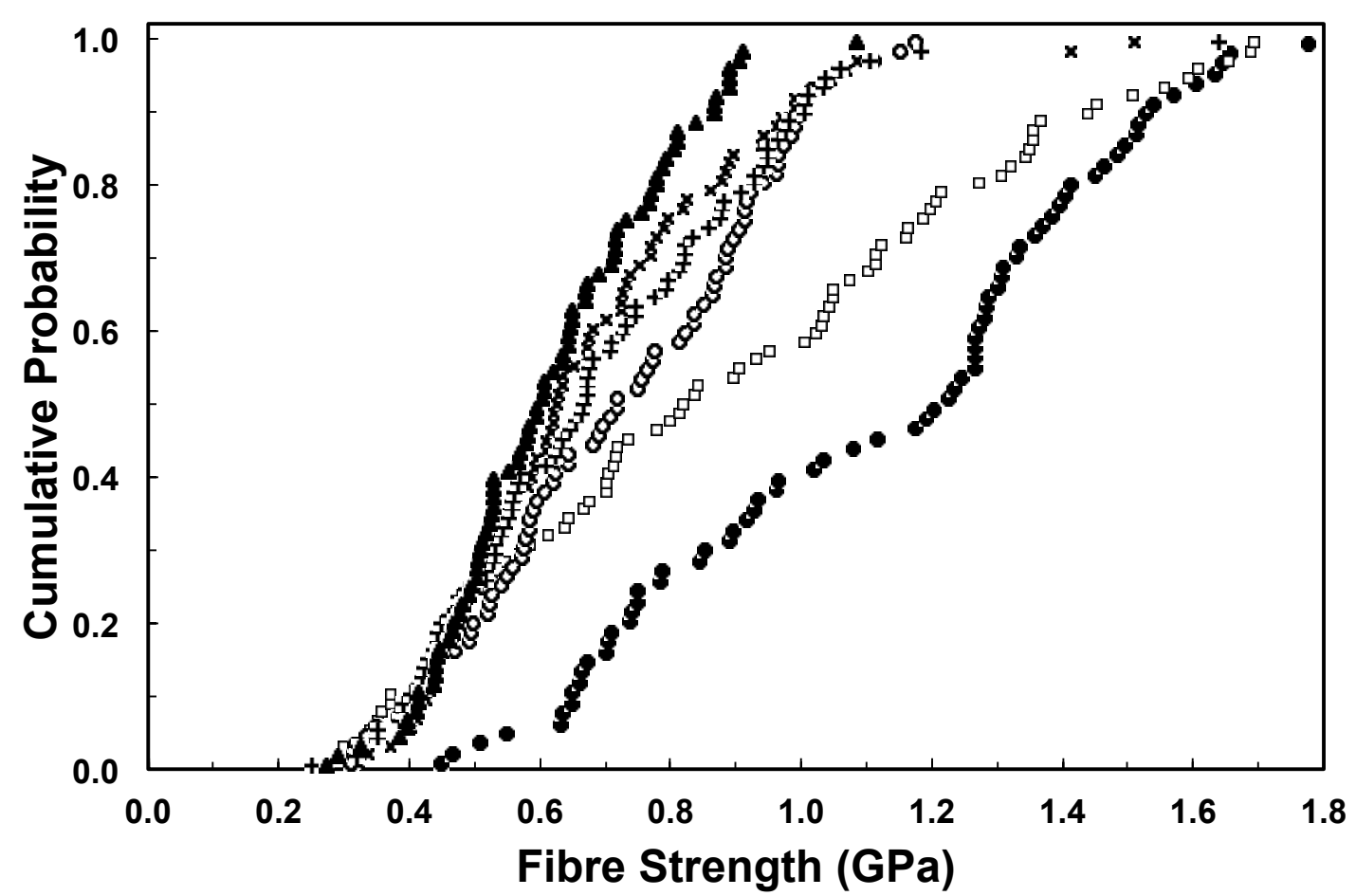

Figure 7 Cumulative failure probability for water sized single fibres after thermal conditioning $\left(23^{\circ} \mathrm{C}, \square 250^{\circ} \mathrm{C}, \bigcirc 300^{\circ} \mathrm{C}, \times 380^{\circ} \mathrm{C},+450^{\circ} \mathrm{C}, \boldsymbol{\Delta} 600^{\circ} \mathrm{C}\right)$.

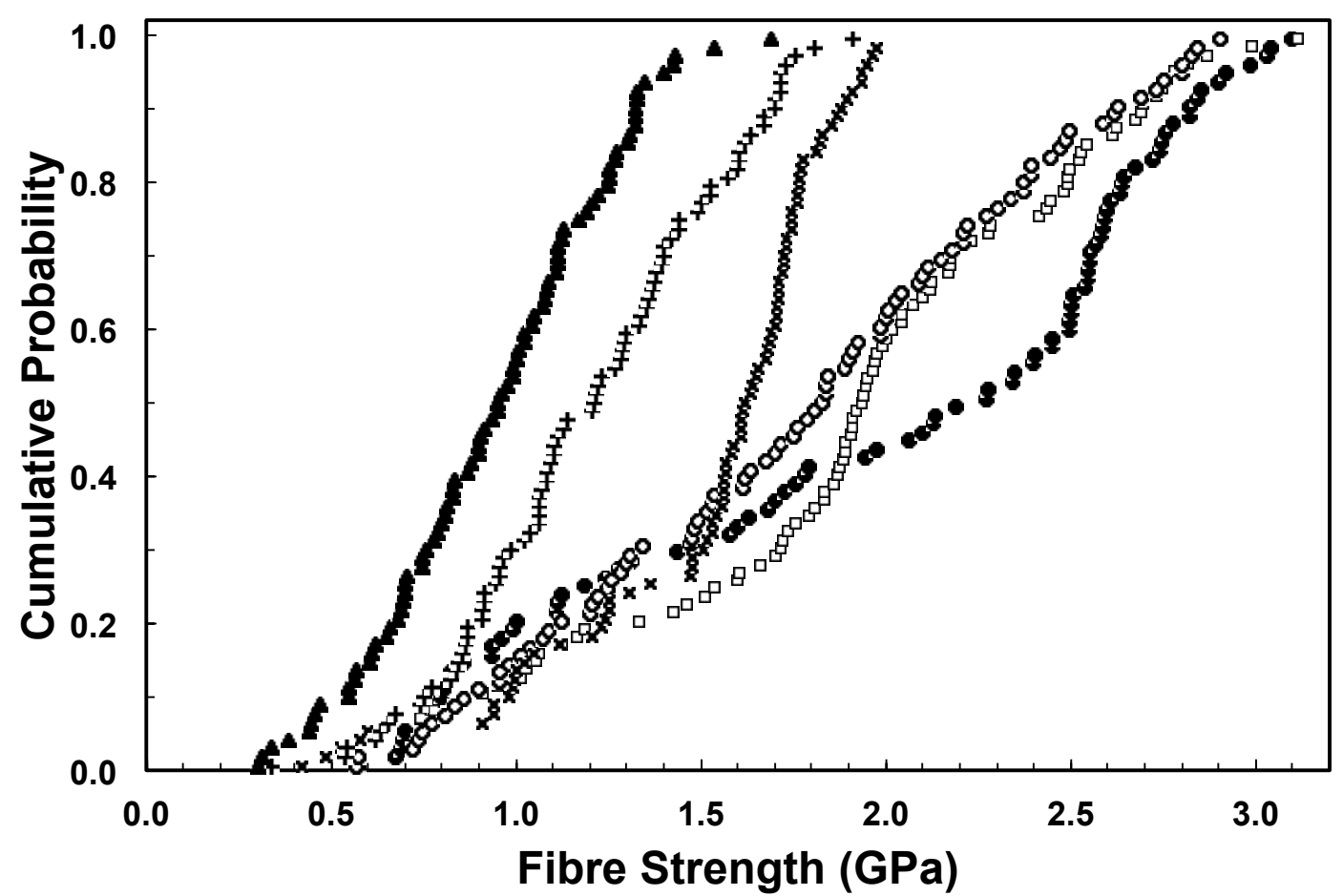

Figure 8 Cumulative failure probability for APS sized single fibres after thermal conditioning $\left(23^{\circ} \mathrm{C}, \square 250^{\circ} \mathrm{C}, \bigcirc 300^{\circ} \mathrm{C}, \times 380^{\circ} \mathrm{C},+450^{\circ} \mathrm{C}, \boldsymbol{\Delta} 600^{\circ} \mathrm{C}\right)$. 


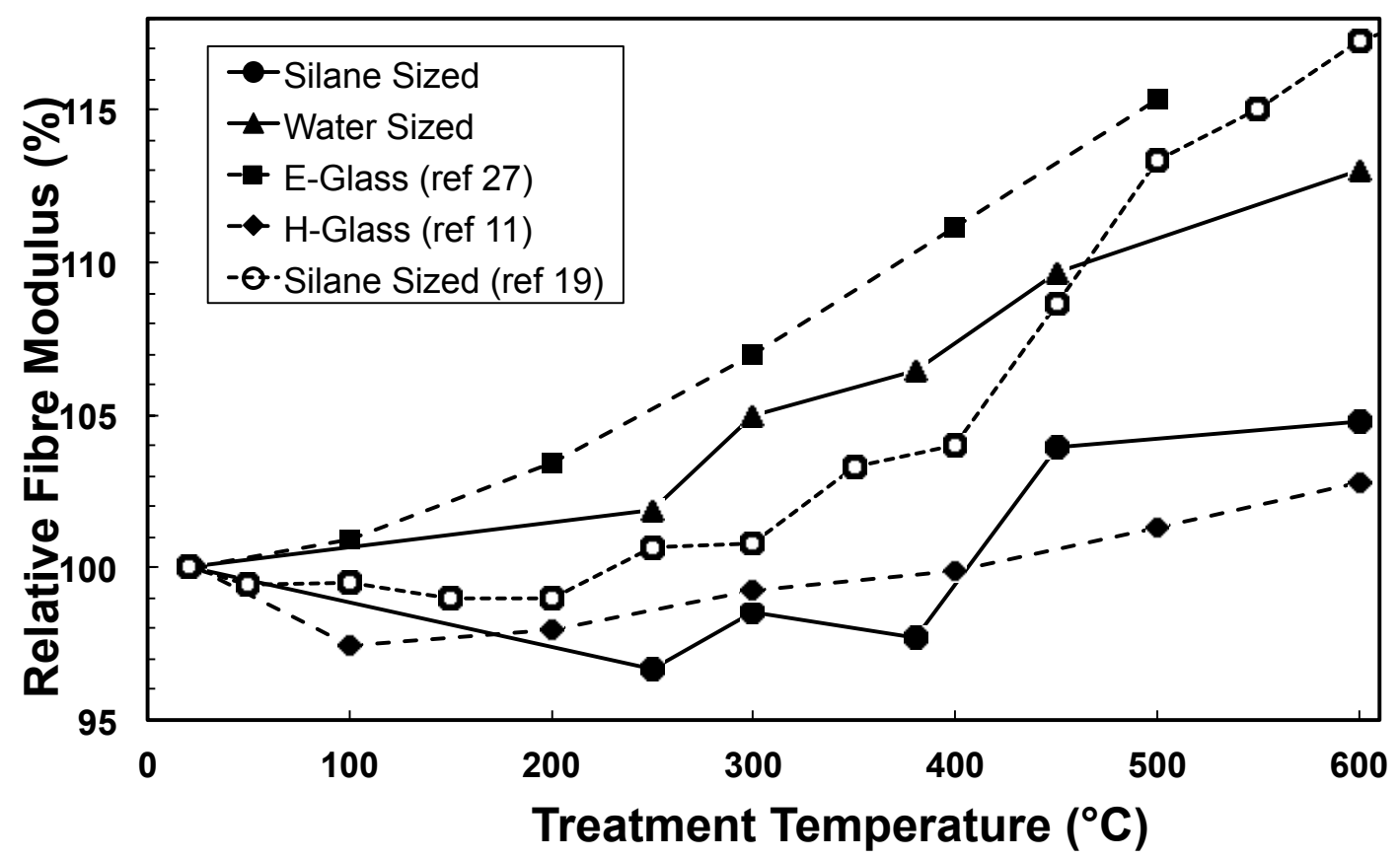

Figure 9 Influence of heat treatment temperature on room temperature glass fibre relative modulus.

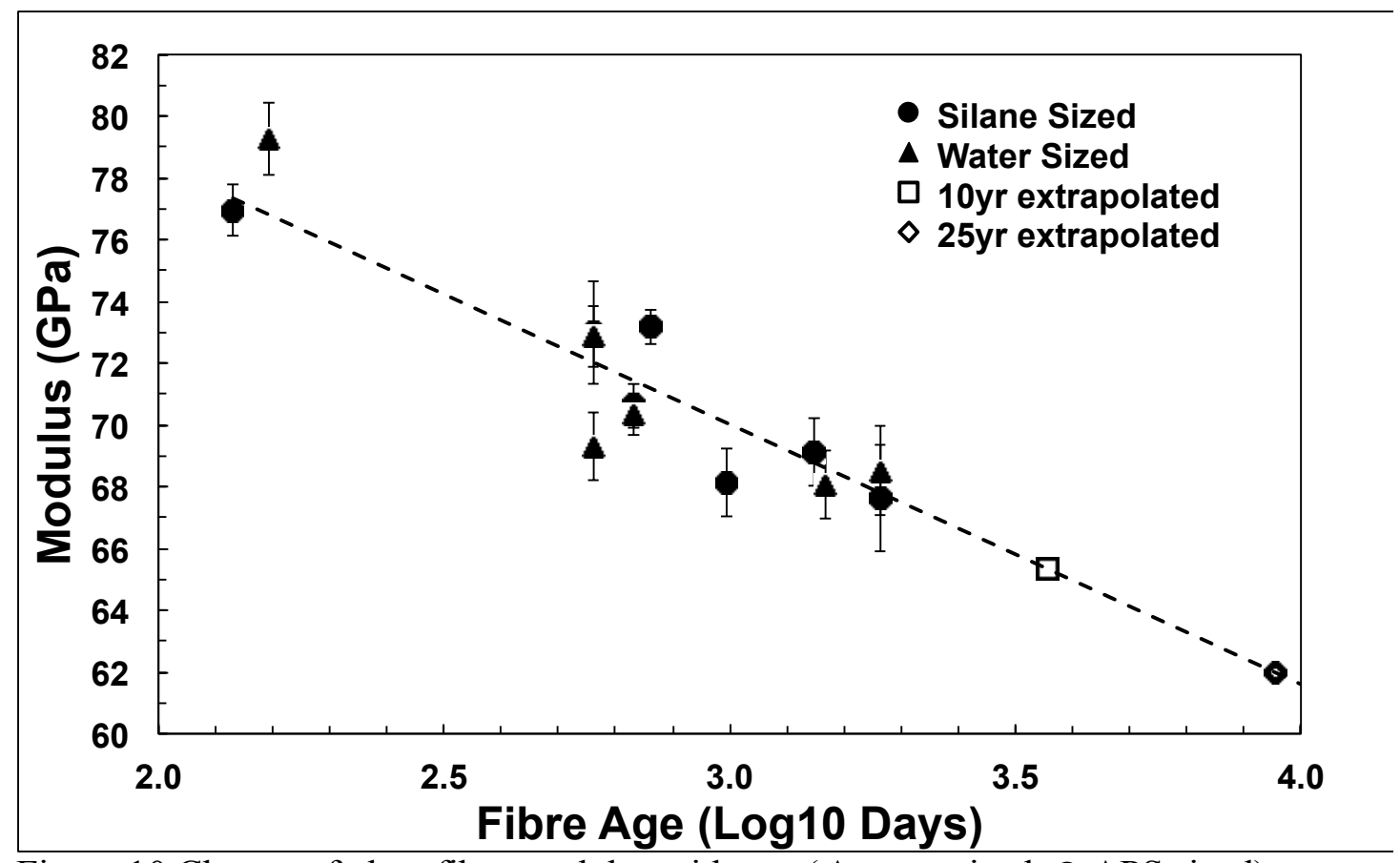

Figure 10 Change of glass fibre modulus with age ( $\boldsymbol{\Delta}$ water sized, $\bullet$ APS sized). 